\title{
Relation of Vitron Theory to 2-Layer-Liquid Immiscibility in Binary Silicate and Borate Glass Melts*
}

\author{
Leroy W. Tilton**
}

(August 1, 1972)

Silica-rich and boron-rich binary glasses resemble clathrates in having host cavities in which modifier oxides may be inclosed without stress as inactive guests until the cavities are approximately filled. Additional modification results in stress both in the holes of the matrix and the cavities of vitrons. Then the structure begins to disintegrate and mixing takes place. The required mole-percent modification is expressed by an equation of the form

$$
100 r_{h}=\frac{100(A-\alpha) \cdot q / 5}{(L-\delta-\alpha)+(A-\alpha) \cdot q / 5}
$$

\begin{abstract}
where $A$ and $\alpha$ are the diameters of vitron cavity and matrix hole, respectively, $L$ is the linear extent of a modifier, and $q$ the proportion of glass-maker that forms vitrons. Computations for 66 glasses have been made to constitute a unified system covering approximately the gamut of typical modifiers.

The identity of parameters $A$ and $\alpha$ for silicates and borates leads to the suggestion that the vitron structure in boric-oxide glass is the regular icosahedron of 20 triangular faces to accommodate a neutral molecule of $\left(\mathrm{B}_{4} \mathrm{O}_{6}\right)_{5}$. Regular octahedra of $\left(\mathrm{B}_{4} \mathrm{O}_{6}\right)_{2}$, if present in the matrix, would provide matrix holes of approximately $\alpha$ in diameter.
\end{abstract}

Key words: Binary borates; binary silicates; boron glass; glass; homogenization of glass melts; immiscible glass melts; immiscibility gaps; silica glass; structure of glass; vitron theory.

\section{Introduction}

These studies of glass were made in part several years ago and brief references to some of the results were mentioned in a summary of vitron theory published in 1963 [12g]. ${ }^{1}$ Meanwhile Levin [5, 28, 37] and co-workers at the National Bureau of Standards had continued their classic reports in the field of glass immiscibility (2-layer liquid type) according to the random-network theory of glass. It was not readily evident how such divergent views of glass structure could lead, almost without exception, to satisfactory agreements in the computation of degree of modification for the termination of immiscibility in binary silicates and borates when the modifiers were known to be mono- and divalent oxides. Also, until certain recent publications on rare-earth oxides, it seemed impossible to understand how unsatisfactory results appeared to follow in many cases when the modifiers were trivalent.

\footnotetext{
*Vitron theory relates only to the short-range order in glasses and glass melts that distinguishes glass from crystal and is not concerned with submicroscopic but relatively gross heterogeneities that are currently being studied in complex glasses or in simple gross heterogeneities that are currently being studied in co
binaries that contain even small percentages of homogenizers.

**An invited paper. The author was formerly a member of the staff of the Optics Section, National Bureau of Standards, Washington, D.C. Present address: 300 Ocean Avenue, A-41, Ocean City, N.J. 08226.

${ }^{1}$ Figures in brackets indicate the literature references at the end of this paper.
}

Delay, however, has led to clarification of vitron theory. Now, in the language of a certain class of nonstoichiometric substances, it is possible to consider silica-rich and borate-rich binary melts as similar to clathrates, or huge molecules within which one type of cage structure imprisons smaller unionized and therefore inert molecules. In silicate glass the guest molecules, or modifying oxides, are imprisoned in the dodecahedral host cavities or vitrons of the silica structure. These vitron cavities are similar to the dodecahedral cavities of liquid hydrates [36].

Silica-rich glass also has additional and smaller (distorted) holes predominantly of a tetrahedral nature within the matrix silica. The holes are considered as bounded by four faces each formed of rings of four, five, or six silicon-oxygen tetrahedra.

As usual in clathrates, host and guest show little or no mutual reaction whether or not they are otherwise compatible. In other words, the forces existing between host and guest molecules are not specifically chemical in nature but only of a general type.

It now becomes clear that only a definite structure theory can apply to glass-former-rich glasses, and only a random theory can cope with conditions after the structure is in great measure destroyed. This dual aspect of the structure of glass was not earlier appreci- 
ated because most experimental processes in the glass field took place on melts that were well modified. Complete modification now is interpreted as meaning melts in which structure has been destroyed or is fine grained.

Furthermore, it is now understandable how the destruction is so early produced by large oxide molecules like the alkalies, whereas it can be so long delayed by using only small alkaline earths as modifiers. Were it not for the use of homogenizers like $\mathrm{Al}_{2} \mathrm{O}_{3}$ the practical range of vitron theory would extend to higher modifications and perhaps would have been accepted more readily.

The tremendous change that takes place during silicate glass making is the breakup of tenacious structure. This is evidenced by the rapid and extensive fall in liquidus temperature when and as modification progresses. During borate glass modification the major change may be the replacement of a relatively weakly connected molecular structure by one with stronger network, and the rise in liquidus temperature is the evidence.

Vitron theory is applicable chiefly to the range from unmodified glass-former glass to the composition at which the liquidus ceases to be horizontal or ceases to show a continuing tendency thereto. Although this is a very restricted region if only large modifiers are used, it becomes a wide one whenever modification is solely dependent on small alkaline earths. Similarly, randomnetwork theory applies principally from that degree of modification where the liquidus completes its first small but rapid rise beyond the eutectic and extends into the region where compounds are formed.

Inbetween lies the important and complex region of glass formation where either or both theories may be helpful. This glass-formation region is often narrow, and more so the wider the vitron region.

Thus, the two theories are complementary rather than antagonistic, and it seems reasonable that boundary conditions, such as the incidence of miscibility, may be predictable from a proper understanding of conditions on either side of the boundary. Also, definite understanding of the modification process should help in the prediction of glass properties and minimize repeated trials in the design and production of glasses suitable for specific purposes.

After Greig [1] in 1927 defined the extent of immiscibility in some simple silicate systems, Kracek [2] combined in a single provocative illustration the silicarich portions of the temperature-composition curves in the phase diagrams of the alkaline-earth and alkali silicates. He announced that on a mole-percent basis decreasing extent of immiscibility (or a tendency thereto) followed the order of basicity of the modifier oxides. It is herein shown that one can equally well say that it follows the order of maximum linear extension of the oxides. Figure 1 shows Kracek's curves as modified and republished by Levin and Block in 1957 [5].

Warren and Pincus [3] used bonding energies, $Z / r$, where $r$ =radius of cation, and also used some geometrical ideas from infinite network theory in com-

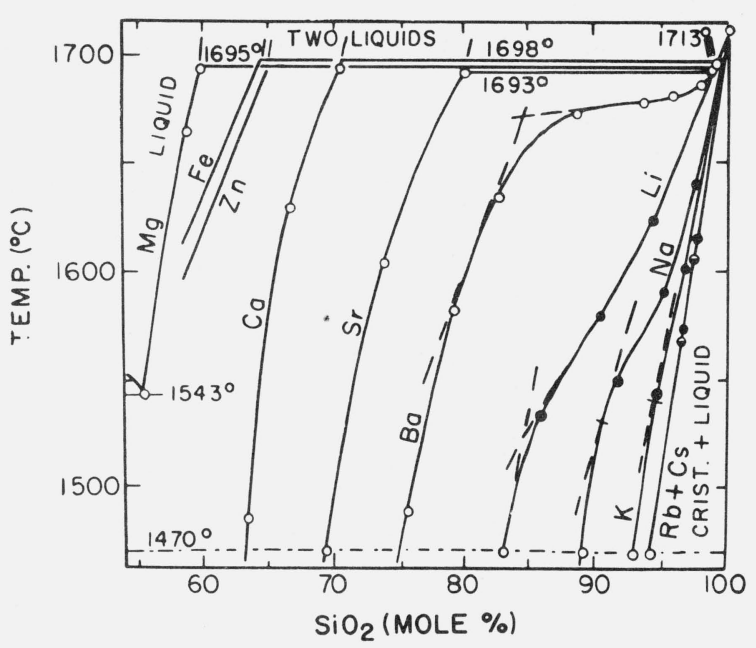

FIGURE 1. Cristobalite melting-point curves, mostly after Kracek [2].

Tangents to alkali silicate S-shaped liquidus curves indicate compositions of postulated metastable modifier-rich liquids. This diagram is unexcelled as an introduction to the study of structure and 2-liquid immiscibility in silicate glasses. (Reproduced as modified by Levin and Block [5]).

puting reasonable values for the approximate limiting compositions of immiscibility in some silicate glasses, but Deitzel [4] favored $Z /\left(r_{1}+r_{2}\right)^{2}$ for expressing the limits.

Levin and Block [5] extended the work of Warren and Pincus and applied crystal chemistry in using not only valence and ionic radii but also coordination number for meticulously and successfully computing limiting compositions of immiscibilities for both silicate and borate glasses.

It was suggested by Glasser, Warshaw, and Roy [6] that the limiting compositions could best be computed by use of $Z / r$ with the introduction of a suitable "valence correction."

The investigators mentioned used chiefly concepts of the random-network theory of the structure of glass. Meanwhile, Preston [7] disagreed with the ideas and interpretations given by $\mathrm{W}$ arren and Pincus. He stated that immiscibility is plausibly due to segregations of different types of structure. This last idea, of course, is logically inferable because in all immiscible silicate melts positive departures from ideality are shown by the liquidus curves. Esin [8] concluded that microheterogeneous structure in liquid silicates was consistent with observed experimental tendencies in immiscibility, surface tension, electrical conductivity, and viscosity.

Relative to this is the work of Forland [9] who studied freezing point depressions and found a remarkably low value of 0.93 units for the entropy of fusion of silica and concluded that "at the melting point the liquid state has almost as much order as the solid state." He states that $\mathrm{SiO}_{2}$ must have a highly ordered and inflexible structure. "By mixing into it a second oxide, this oxide has to be incorporated without major disturbances in the structure . . . This property of liquid $\mathrm{SiO}_{2}$ seems to cause the formation of certain groups in the liquid and may be the cause of the liquid immiscibility in some silicate systems." 
An important principle that was noticed and announced early in the course of vitron study was the existence of a modificational threshold for ionization in glasses. A strong note in favor of delayed ionization was sounded by R. W. Douglas [17] at the conference on noncrystalline solids at Alfred, New York, in 1958 when he said concerning positive departures from ideality and immiscibilities in silica-rich binary silicates: "This clearly indicates that the ionization of the network-modifying oxides is incomplete ..." In retrospect, it can be realized that the electrical experiments on which ionization theory [16] rests do not show that the theory can extend with equal validity to low degrees of modification.

Moreover, it has been reported [20] that the thermal expansion of alkali silicate melts increases very sharply when alkali content exceeds $12 \pm 2$ mole percent. White [21], in particular, recognized this as "the first direct proof that a fundamental change in liquid (alkali) silicates occurs near 12 percent $\mathrm{R}_{2} \mathrm{O}$." For the alkalineearth silicates the corresponding percentages for onset of "typically ionic" thermal expansion can be estimated from the curves of Tomlinson [22] et al. (their fig. 4 reproduced here as fig. 2). For $\mathrm{BaO}$ the modification is

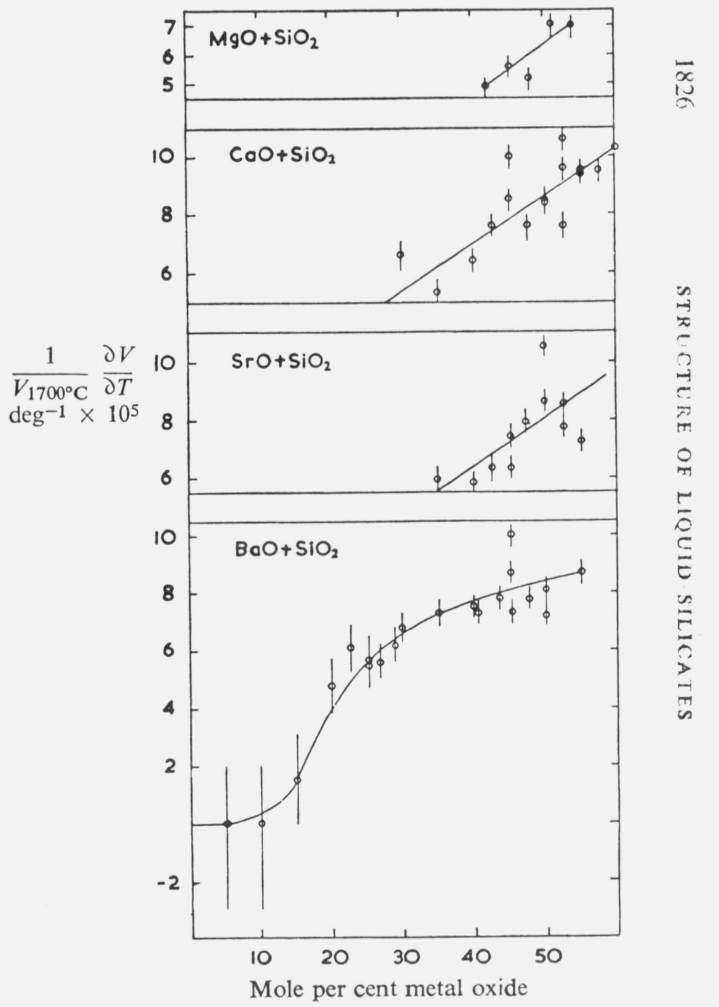

Figure 2. Expansivity curves published by Tomlinson et al. [22]. One may infer that typically ionic thermal expansion begins in quantity for alkaline-earth begin to disintegrate.

certainly as high as 15 percent before expansion begins in quantity; for $\mathrm{SrO}, \mathrm{CaO}$, and $\mathrm{MgO}$ it may be inferred that the percentage modification at incidence is near or above 20,29 , and 40 percent, respectively.
Regardless of evidence, many investigators of silicate glasses still accept not only the conventional idea that modifier cations enter the "voids" but also the idea that the oxygens enter the network itself by the immediate "breaking of oxygen bridges" between network silicon and oxygen. ${ }^{2}$ Furthermore it has been assumed, according to the uniform random-network theory, that the voids in glass are more or less of one average size.

In contrast, the writer [12] developed the vitron theory according to which silica glass itself is a composite of 0.305 "vitron" having nearly regular pentagonal dodecahedral cavities and 0.695 matrix having much smaller and irregular (probably roughly tetrahedral) holes. ${ }^{3}$ The structure in each case is basically of connected silicon-oxygen tetrahedra, but whereas the vitron portion has the definite (but slightly distorted) structure of pentagonal dodecahedra (as evidenced by the peaks on the various radial distribution curves) the denser matrix corresponds to the general blurred background of the scattering in the x-ray diffraction patterns. Thus, the matrix may have rings other than penta and considerable variation in the $\mathrm{Si}-\mathrm{O}-\mathrm{Si}$ angles, and perhaps in the shape of matrix holes which are predominantly very small as compared with the vitron cavities.

Obviously the $\mathrm{Si}-\mathrm{O}-\mathrm{Si}$ angles in such a dual silica cannot be comprehensively determined by x-rays. The characteristics of only the vitron or regular portion can be measured and here the evidence is consistent with the assumption of $180^{\circ}$ as originally made by Warren [13] for a nearly unstressed high-temperature condition in tetrahedra.

These proposed vitrons are, from a structural viewpoint, somewhat similar to pseudonuclei more recently described in general terms by Bernal [14] for certain liquids and by Ginell [15] for the basis of his "asymetric cluster picture of glass structure."

From the volume proportion of vitron (computed density 1.986) in fused silica (density 2.203), one may compute (by additivity of specific volumes) a density of 2.31 for the matrix. This exceeds all values reported for the end product of the neutron irradiation of either quartz or vitreous silica and is about as dense as crystobalite in which the cavities might be able to include, at maximum, one oxygen atom. The matrix can be considered as the solvent in which the vitrons are immersed. The matrix probably has a melting range not far above $1700{ }^{\circ} \mathrm{C}$, but silica vitrons may persist to temperatures above $2000^{\circ}$ (see sec. 5). Internal stresses and small quantities of modifiers and impurities, say 0.5 percent, may reduce the matrix liquidus temperature by several degrees $\mathrm{C}$.

${ }^{2}$ Interpenetration of cation and network was quantitatively discussed by Dietzel [10] in 1943 and by Dietzel and Sheybany [11] in 1948. On the conventional basis alone, they came to the less than satisfactory conclusion that 142 percent (sic) of the $\mathrm{Li}$ ions must be lost in the voids in silica-rich glasses in order to account in this way for the observed densities of the binary glasses. Vitron theory early suggested as an alternative that oxygen as well as cation can and does enter the voids.

${ }^{3}$ The volume proportion of vitron, i.e., the somewhat regular structure in silica glass, was first estimated graphically (see L. W. T. paper [12(e)], p. 16) from interpenetration data on alkali silicates as at least 28 percent. Later, from a vitron model and published im. miscibility data on $\mathrm{SiO}_{2} \cdot \mathrm{MgO}$, an independent and probably more reliable computation led to 30.5 percent vitron. (See L.W.T. paper [12(g)], p. 433.) 
A probable structure for the matrix is a network of some rings of 6 and 7 tetrahedra in addition to the more probable penta rings. The $\mathrm{Si}-\mathrm{O}-\mathrm{Si}$ angles in this matrix are necessarily variable over a considerable range and probably considerably smaller than $180^{\circ}$. Perhaps the majority of holes in the matrix may be irregularly tetrahedral in form with the four distorted faces, each consisting, on average, of rings of 5 tetrahedra. ${ }^{4}$ It is unlikely that many representative holes in the matrix can have both the spherical size to accommodate an oxygen atom and also the added linear dimension to accommodate any commonly used glass modifying oxide without serious stresses in the matrix network. In other words, $\mathrm{BeO}$ may be the only modifying oxide molecule small enough to enter freely into holes in the matrix.

The method used here in studying immiscibility is primarily geometrical in nature. The general question is simply: Can we compute how much oxide can be added to molten silica and remain so concealed and inclosed in vitron cavities that the silica-rich portion of the liquidus remains horizontal (or tends to be that way) until the vitron cavities are so reduced in residual capacity as to equal the matrix holes in their original capacity? To answer, it is necessary to evaluate or estimate:

(a) The vitron geometry and density. (See L.W.T. [12(b)] 1959.)

(b) The threshold for ionization. (See sec. 2, this paper.)

(c) Relative volumes of vitron and matrix. (See footnote 3 , this paper.)

(d) The matrix geometry. (See footnote 3, this paper.)

In particular, the procedures make use of computations of the sizes of modifier oxides as compared with cavities in silica-rich and boron-rich glasses.

\section{Maximum Extension of Glass Modifiers}

In preliminary work on some silicates during this investigation of immiscibility, the concept of maximum individual oxide extension, $L$, at high temperatures was tried graphically as a measure of the effectiveness of each of a group of similar modifier oxide molecules in causing damaging stress when inclosed within vitron cavities. Later it was found that $L$ is very satisfactory, but not perfect, for use in computing the termination of immiscibility in borates as well as in silicates. Some of the difficulties of precise computation are mentioned in connection with eq (3) in section 3 .

\footnotetext{
${ }^{4}$ If the holes of the matrix have tetrahedral character and four faces of 5-ring tetrahedra each, there would be $0.8 \mathrm{SiO}_{2}$ per hole; if the faces are of 6 rings, there would be one $\mathrm{SiO}_{2}$ per hole, and if of 7 rings there would be $1.2 \mathrm{SiO}_{2}$ per hole. Thus a group of 5 holes of the matrix would require about as much $\mathrm{SiO}_{2}$ as is required for a vitron cage, namely $5 \mathrm{SiO}_{2}$ This estimate, of course, accords with the assumption made in constructing table 3 on p. 15 of L.W.T. paper [12(b)] for use with $\mathrm{R}_{2} \mathrm{O}$ modifiers, namely that in miscible glasses the modifiers would be approximately uniformly distributed with respect to silica (whether in vitron or matrix) vitron or matrix). As a consequence, all the inferences that were drawn concerning number of $\mathrm{R}_{2} \mathrm{O}$ molecules per vitron cavity at the "breaks" and special points on the curves of property versus composition that were discussed in former papers on vitron theory, a approximately as valid as would have been the case if said table 3 had been made with present ideas of the matrix and the value of $q=0.305$ as the volume proportion of silica that forms vitrons.
}

$L$ may be simply expressed as the sum of diameters of atoms for monovalent oxides $\mathrm{R}_{2} \mathrm{O}$ and divalent oxide modifiers RO. That is, $L=\left(\mathrm{D}_{\mathrm{O}}+2 \mathrm{D}_{\mathrm{R}}\right)$ and $L=\left(\mathrm{D}_{\mathrm{O}}+\mathrm{D}_{\mathrm{R}}\right)$ respectively.

For $\mathrm{R}_{2} \mathrm{O}_{3}$ modifiers (not reduced at glass-processing temperatures), the diameter of the circumsphere is the corresponding maximum extension. If the radius of the cation is less than $1.10 \AA$, the maximum extension is constant at the diameter of a sphere that incloses the three touching oxygens, namely

$$
L=2 r_{0}(1+(2 / 3) \sqrt{3})
$$

or $5.7 \AA$ for $R_{0}=1.32 \AA$.

If trivalent cation radii are larger than approximately $0.85 \AA$, one must consider the overall cation extension. Each continues to touch 3 oxygens, but cannot touch the other cation. The cation centers lie on opposite sides of a central plane determined by the three oxygens. In such cases, the maximum cation extension becomes larger than the diameter for the circumsphere for the three touching oxygens, that is in excess of $5.7 \AA$, which is also the maximum inscribed sphere inside a vitron. Thus it appears that trivalent modifiers, acting as such, would not be of interest in 2-layer-liquid immiscibilities for silicate or borate glasses. Even single molecules of trivalent modifiers should produce some stress ionization and miscibility starting almost immediately if they can withstand high temperatures, and some of them are well known as homogenizers.

From eq (1) and discussion above it might be thought, as already indicated, that trivalent oxides (sesquioxides) would be of little interest in studies of immiscibility in silicates. On the contrary, immiscibilities have been reported for about as many sesquioxides as for all mono- and divalent oxides.

The highly refractory $\mathrm{Al}_{2} \mathrm{O}_{3}$ has a molecular size (maximum-extent) of $5.7 \AA$, which places it among oxides that have an S-shaped liquidus, a temperaturecomposition curve with a tendency toward metastable immiscibility terminating near 13 mole percent of modification. Experimentally, Aramaki and Roy [27] found only a nearly flat liquidus. No reports have been made of any immiscible liquids and the use of $\mathrm{Al}_{2} \mathrm{O}_{3}$ as an homogenizer is well known. A similar example is the strong glass former $\mathrm{B}_{2} \mathrm{O}_{3}$ which shows no 2-liquid layer in binary silicate melts.

A third trivalent oxide modifier of the same maximum extent, $5.7 \AA$, but different character is $\mathrm{Fe}_{2} \mathrm{O}_{3}$. In this case it is commonly said that the 2-liquid layer produced in the binary melt arises from $\mathrm{FeO}$ as the only modifier even though ferric iron was introduced and $\mathrm{FeO}$ is known to be of little stability in air.

A fourth trivalent oxide is $\mathrm{Cr}_{2} \mathrm{O}_{3}$ and here the results are somewhat ambiguous. This oxide also is said to be at least partially reduced at high temperatures. There is some discrepancy among experimental reports, but it seems probable that only one 2 -liquid area of immiscibility is formed. The miscibility gap is usually labeled as that for $\mathrm{Cr}_{2} \mathrm{O}_{3}$, but the 
gap itself is almost exactly that predicted by vitron theory for $(\mathrm{CrO})$ in silicate melts and the same is true for borate melts.

The author of this paper suggests that similar partial reduction in the furnace in the course of glass melting has occurred when many other sesquioxides have been used as glass modifiers; that only one 2 -liquid region is present in such cases in binary melts; and that the termination of the gap has usually been adequately determined but erroneously assigned to the sesquioxide that was used in the batch rather than to the divalent oxide (RO) to which it was partially reduced. Furthermore, it seems that numerous analyses of cation in glasses quenched from terminal conditions have been made without regard to its valence condition.

Indeed, one confirmatory experiment is of record, as published by Shafer and Suits [44] in which mention is made of a region of liquid immiscibility in the system $\mathrm{EuO}-\mathrm{B}_{2} \mathrm{O}_{3}$ appearing to extend "to about 15 to $20 \%$ EuO." In a private communication, Shafer says: "After looking at some of our data again, I am convinced that compositions of $20-24 \% \mathrm{EuO}$ could easily be within the immiscibility region." The best value for termination of the gap in " $\mathrm{Eu}_{2} \mathrm{O}_{3}$ " is 26.7 mole percent, and the vitron prediction for $(\mathrm{EuO})$ is 25.5 mole percent. The finding of this gap was a side issue in the Shafer-Suits paper, but they state: "All glass specimens were chemically analyzed for divalent europium, total europium, boron, and aluminum."

If large glass-forming quadrivalent oxides are used in silica-rich or boron-rich binary glasses, immiscibility cannot result because networks may interpenetrate or the sizes of the large oxides may be such that probably no one of them can be contained within an unstressed vitron wherein the maximum diameter of an inclosable sphere is only $5.7 \AA$. Nor does it seem probable that strong glass-former oxides would be reduced in the furnace to smaller modifier oxides that might enter silicate or borate glasses. These quadrivalent oxides are appreciably larger than $\mathrm{SiO}_{2}$. Thus, they may be expected to form larger vitrons than does $\mathrm{SiO}_{2}$ or $\mathrm{B}_{2} \mathrm{O}_{3}$, and have correspondingly larger holes in their matrices. It is interesting to surmise that some of the small modifiers would be completely miscible in largecation quadrivalent glasses for the same reason that $\mathrm{BeO}$ is miscible in $\mathrm{SiO}_{2}$.

Before announcing the above conclusions, it seemed advisable to place miscibility computations on a precise quantitative basis.

\section{Equations for Limit of Immiscibility}

As mentioned in the Introduction, glass maker-rich glasses are similar to clathrates within which one type of structure imprisons another. Immiscibility results if modifiers can be enclosed in the large cavities of vitrons but not in the small holes in the matrix. Ionization which induces miscibility begins in quantity only when the guests start to disrupt the host walls, either because of large guest size or their collective effect.
In either case, ionization begins after it becomes about equally difficult for vitron or matrix to inclose an additional oxide molecule without significant stress and strain. This is called the condition of equal voids.

In an earlier paper (L.W.T. [12(g)] footnote, p. 433) $N$, the number of oxide molecules per cavity, was expressed as

$$
N=5 r / q(1-r)
$$

where $q$ is the proportion of silica molecules available for the formation of vitrons at any proportion of modifier molecules, $r$, and 5 is the number of molecules of interior $\mathrm{SiO}_{2}$ forming the walls of a vitron cavity (and thus not part of the walls of adjacent cavities or of the matrix). In other words, the number of cavities is $C=(1-r)(q / 5)$. For computing the modification corresponding to any particular $N$, eq (2) is conveniently used as $r=(q / 5) N /[1+(q / 5) N]$.

The value of $q$ can be determined from eq (2) if any pair of reliable corresponding values of $N$ and $r$ are available. For a modifier with sufficiently small cation, $N_{\max }=13$ can be found from the known vitron geometry and a model consisting of 13 spheres representing oxygens in central packing -12 touching one at their center to form a loosely packed cluster in which the outer 12 do not necessarily touch each other. The three touching oxygens on each of 6 axes have a combined extension of $7.92 \AA$ which exceeds the face-toface distance within the vitron cavity, but protrudes insignificantly beyond the $7.8 \AA$ diameter of the volume-equivalent sphere. The looseness of packing may provide space for small cations.

From the experimental data listed in this paper (table II), a few values of $r_{h}$ for modifiers having small cations were plotted versus $(L-\alpha)$. Then a smoothed value of $r_{h}$ for $(\mathrm{GaO})$ was read from a smooth curve for use with $N_{h}$ for $(\mathrm{GaO})$ assuming that $N_{h}=N_{\max }{ }^{5}$ From eq (2) the values $q=0.31$ for silicates and $q=0.38$ for borates were then obtained.

Precise computation of extent of immiscibility, even in simple binary glasses, seems difficult because the incidence of homogeneity is dependent not only on differential volumes but also on peripheral cavity strain which may be introduced at a single point long before volume filling is concluded. Either way, the host structure is vulnerable. There is no problem about computing total volumes of the vitron cavities and no important problem about the host holes of the matrix, but a real problem seems present in the accidental packing of the guest oxides. Futile studies of packings and porosities were made, and various trials were unsuccessful with actual oxide volumes, with their spherical envelopes, and also with volumes of their inclosing parallelopipeds. The matter is further complicated by possibilities that parts of some oxides may protrude through common interfaces and into adjacent cavities or holes without damaging stress that will break $\mathrm{Si}-\mathrm{O}$ bonds.

${ }^{5}$ Precise data are not available for $\Delta N=N_{\max }-N_{h}$. It is estimated as 0.2 or 0.3 . The parameter $\alpha$ is defined below and in table I. 
In view of a successful graphic use of maximum extent (M.E.) of oxides in preliminary tests, it seemed that linear distance, $L=$ M.E., might be useful also in computations as a measure of ability to cause damaging stress. For a beginning, the average linear effective or "pseudo capacity" of a tetrahedral matrix hole was represented by diameter $\alpha \AA$ and estimated to be greater than 2.6 or 2.8 (diam. of oxygen atom), perhaps about $3.5 \AA$ (linear extent of $\mathrm{BeO}$ which is miscible in all proportions in silica glass). Next, the effective or pseudo capacity of a vitron cavity was represented by a diameter of $A$ angstroms and estimated to be $7.81 \AA$, the diameter of the vitron cavity's volumeequivalent sphere. Then $(A-\alpha)$ is the total available pseudo capacity of a vitron for oxide storage before equalization of voids in cavities of vitrons and holes of matrix and the incidence of homogenization. At this stage one might try to express the required number, $N_{h}$, of modifier oxides per vitron cavity at incidence of homogenization as $N_{h}=(A-\alpha) / L$, but this would neglect the cooperative protrusion of part of an oxide into the holes of the matrix. By using $(L-\alpha)$ instead of $L, N_{h}=(A-\alpha) /(L-\alpha)$. The usefulness of this expression can be tested by a trial computation of $N_{h}$ for the oxide $(\mathrm{GaO})$, the smallest modifier that seems available for the test. The value of $N_{h}$ so obtained is 8.3 as compared with about 13 that should be found, as will be understood from the discussion in the first three paragraphs of this section. Further improvement in $N_{h}$ may result from arbitrary changes in parameters $A$ or $\alpha$, or by a decrease in the computed value of $L$, which is merely a conveniently variable property of the modifying oxides. Accordingly $L$ is reduced by $\delta=0.05 L$ (a packing factor) and

$$
N_{h}=(A-\alpha) /(L-\delta-\alpha)
$$

which gives as $N_{h}$ for $(\mathrm{GaO})$ the reasonable value 12.9 molecules per cavity.

After substituting eq (3) in (2), the value of modification in mole percent at incidence of homogenization is

$$
100 r_{h}=\frac{100(A-\alpha) \cdot q / 5}{(L-\delta-\alpha)+(A-\alpha) \cdot q / 5}
$$

which was found to be valid for values of $L$ between those for $\mathrm{K}_{2} \mathrm{O}$ and $(\mathrm{GaO})$.

A surprising thing about miscibility gaps in binary glasses is the close agreement between the gaps in silicates and borates for the same oxides. Because of this, the equations (3) and (4) were used for both sets of published experimental data, and the parameters are listed in table I.

Values of atomic radii by Ahrens [54] were preferred and used throughout ${ }^{6}$ except that for $\mathrm{Bi}$ the value of

\footnotetext{
${ }^{6}$ In computations the values of radii for $\mathrm{R}^{3+}$ were used even for those modifiers assumed to be reduced in the melts from $\mathrm{R}^{3+}$ to a divalency. In a few cases, the $\mathrm{R}^{2+}$ radii were tried and found to yield values of $100 r_{h}$ only 10 percent lower than with the $\mathrm{R}^{3+}$ values. Cationi behavior of this nature has been reported among rare-earth nitrides [38]. Another evidence of divalency of rare-earth cations with ${ }^{3+}$ radii may be the report that some of these atoms can be substituted for $\mathrm{Ca}^{2+}$ crystal sites [39].
}

TABle I. Parameters for Equations (3) and (4)

\begin{tabular}{l|c|c|c|c}
\hline \hline & $A$ & $\delta$ & $\alpha$ & $q$ \\
\cline { 2 - 5 } For silicates........ & angstroms & & angstroms & \\
For borates.......... & 7.81 & $0.05 L$ & 3.34 & 0.31 \\
\hline
\end{tabular}

$A$ is diameter of spheres each equivalent in volume to a vitron cavity;

$\delta$ is a correction to oxide extension, $L$, perhaps a packing factor;

$\alpha$ is diameter of spherical holes in matrix each capable of holding one molecule of $\mathrm{BeO}$;

$q$ for silica is the vitron proportion thereof, independently computed and published in 1963, and for borates the value obtained from eq (2) as mentioned in section 3.

$1.20 \AA$ was used, following Levin $[28,30]$ and associates at the National Bureau of Standards, and that for oxygen 1.32 was used as in glass technology.

Equations (3) and (4) with the parameters of table I were used for computing the required conditions, $N_{h}$ and $r_{h}$, for incidence of homogenization of silicate and borate glasses, and the computed values are given in columns (1), (4), (10), and (11) of table II for comparison with experimental results (as selected by Levin and associates, columns (3) and (13), and by them adequately referenced). The values $\Delta$, column (9) for borates minus silicates, speak for the precision of the computations which were made with a slide rule.

In table II the formulae for numerous divalent oxides known to be unstable in air are inclosed in parentheses. The corresponding values of $100 r_{h}$ are for divalent modifiers preserved in the glasses. In one instance, $(\mathrm{EuO})$, in borate glass, the predicted value has been approximately confirmed [44]. (See sec. 2 above.) In most other cases of unstable divalent modifiers, the only observed values available for listing in the table are those which have been published for the sesquioxides of the same cations. In all cases, except for $(\mathrm{CoO})$, these published observed values for $\mathrm{R}_{2} \mathrm{O}_{3}$ agree very well with the predicated values for (RO). In only five cases, $\mathrm{CaO}, \mathrm{CdO}, \mathrm{ZnO}, \mathrm{MgO}$, and ( $\mathrm{CoO}$ ), are the observed values discordant - all too high - and the cause may be evaporation during melting or modifier acting in part as glass former.

Columns (4) and (10) are of course equal because the silicate and borate cavities are equal in size. The plus signs appear exclusively in column (9) because there are more cavities in borates than in silicates at any given mole-percent composition. It is to be expected that columns (2) and (12) should show predominently negative signs. Even the accepted values of observed $100 r_{h}$ are somewhat higher than the computed values because some small amounts of modifier are found in the predominently glass-maker-rich liquids, not in the modifier-rich liquids. To this extent, perhaps 1 or 2 percent of mix, there is loss of modifier as such, and the total modification actually required exceeds the amount judged as necessary according to the composition of the modifier-rich liquid.

In brief, vitron theory predicts that all sesquioxides of rare earths, including $\mathrm{Ce}_{2} \mathrm{O}$, and also the oxides 
$\mathrm{Bi}_{2} \mathrm{O}_{3}, \mathrm{Cr}_{2} \mathrm{O}_{3}$, and $\mathrm{Ga}_{2} \mathrm{O}_{3}$, are at least partially reduced to divalency in the furnace at glass-melt temperatures and preserved in the glass from reoxidation [40]. ${ }^{7}$

The use of eqs (3) and (4) in computing the degree of modification necessary for homogenization in binary silicates and borates is the most simple and direct evidence so far produced for the existence of vitrons in glass.

In this connection it should be emphasized that the parameters of these equations were taken from vitron theory approximately as published some years ago and fixed within relatively narrow limits. Only one constant, $q=0.38$, for borates, was adjusted to fit data. The residuals $\mathrm{c}^{-} \mathrm{o}$ (columns 2 and 12) of table II do not

\footnotetext{
${ }^{7}$ Here it may be mentioned that Cohen [41] has published papers on the partial reduction by $\mathrm{x}$-irradiation of trivalent rare-earth cations to divalency and their preservation in glasses.
}

exceed the imprecision of the experimental data. Only small systematic trends indicate that the form of eq (4), or the values for its parameters, are not perfectly suitable for the use made thereof.

That vitron geometry may be used in the formulation of glasses of specified densities is indicated by the computations in the next section. Also a correlation between vitron theory and neucleation is shown in section 5 .

\section{Density of Molten Binary Silicate Glasses at Homogenization}

If one knows the degree of modification, $100 r_{h}$, at which immiscibility (or tendency thereto) terminates, it is possible to approximately compute the density of

TABLE II. Mole-Percent $\mid$ Modification for Incipient Homogenization (Computed by equations 3 and 4 )

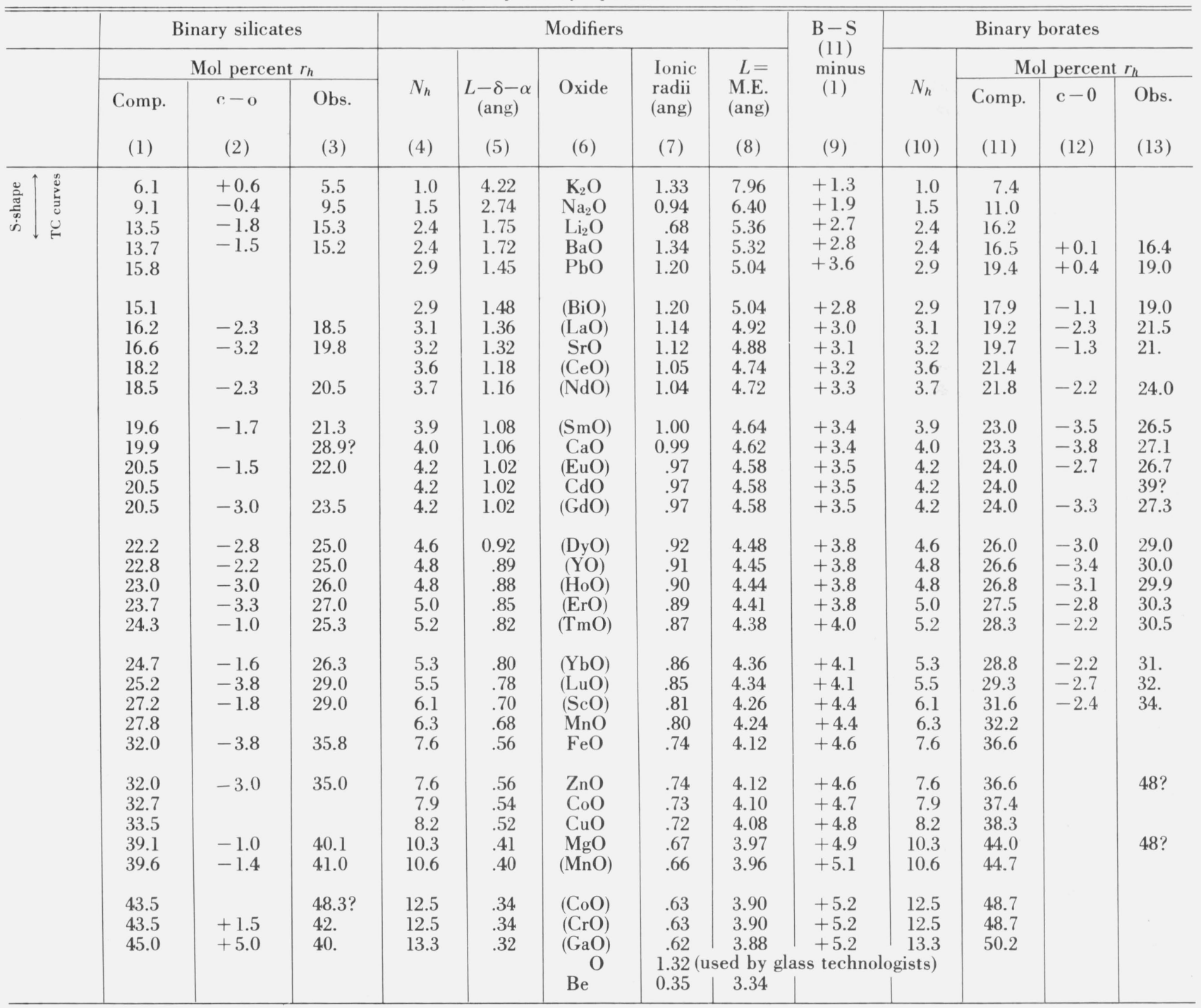


a glass from the molecular weights of silica and modifier, the volume $\left(251.2 \AA^{3}\right)$ of a vitron, the density $\left(2.203 \mathrm{~g} / \mathrm{cm}^{3}\right)$ of vitreous silica, and the volume ratio (2.28) of matrix to vitron therein. Since the atomic weight of silicon is 28.086 and of oxygen 15.9995, the weight of $5 \mathrm{SiO}_{2}$ in the framework of a vitron is 300.4 gfw/avogadro's number or $498.8 \mathrm{~g} \times 10^{-24}$. After adding the corresponding weight of the $N_{h}$ modifiers and dividing by the volume of a vitron, one obtains the density of the vitron portion $(q=0.305)$ of the glass. The deduction of $2.31 \mathrm{~g} / \mathrm{cm}^{3}$ as the density of the matrix portion $(1-q=0.695)$ of the glass was mentioned in section 1 of this paper. The glass densities in table III were computed as outlined above and by use of the additivity of specific volumes.

The observed densities for the alkaline-earth glasses are extrapolated from values given by Tomlinson, Heynes, and Bockris [22] for $1700{ }^{\circ} \mathrm{C}$. Those for the alkali silicates are from Bockris, Tomlinson, and White [20] for $1400^{\circ} \mathrm{C}$.

Note that at melt temperatures the densities of the oxides $\mathrm{Li}_{2} \mathrm{O}, \mathrm{Na}_{2} \mathrm{O}$, and $\mathrm{K}_{2} \mathrm{O}$ (which show only tendencies toward immiscibility in binary silicate glasses) are about the same as or only slightly different from that of silica; whereas the oxides $\mathrm{MgO}, \mathrm{CaO}$, and $\mathrm{SrO}$ (which produce definite immiscibility) are all of considerably greater density than silica. Whenever by chance a vitron becomes modified to the extent of containing one or two molecules of one of these denser oxides, it tends to sink in the melt where it has greater probability of further modification, whereas the empty vitrons tend to float where the probability of modification is lowest. In this way, modifier-rich liquid tends to become richer and forms a lower layer and nearly pure silica forms a top layer, as has been observed and reported.

TABLE III. Densities at Incipient Homogenization

\begin{tabular}{c|c|c|c|c|c|c|c}
\hline \hline Oxide & $\mathrm{MgO}$ & $\mathrm{CaO}$ & $\mathrm{SrO}$ & $\mathrm{BaO}$ & $\mathrm{Li}_{2} \mathrm{O}$ & $\mathrm{Na}_{2} \mathrm{O}$ & $\mathrm{K}_{2} \mathrm{O}$ \\
\hline Computed...... & 2.74 & 2.61 & 2.72 & 2.75 & 2.27 & 2.24 & 2.23 \\
c-o.............. & +.29 & +.17 & .0 & +.03 & +.08 & +.02 & .0 \\
Observed....... & 2.45 & 2.44 & $(2.7)$ & 2.72 & 2.19 & 2.22 & 2.23 \\
\hline
\end{tabular}

\section{Nucleation}

According to vitron theory, the pseudonuclei shortrange structure forms at high temperatures and persists to distinguish a glass melt from one of cristobalite. The $\mathrm{Si}-\mathrm{O}-\mathrm{Si}$ angles of $180^{\circ}$ are to be expected as the highest temperature form of connected tetrahedra, and pentagonal rings of such tetrahedra (all centers of $\mathrm{Si}-\mathrm{O}-\mathrm{Si}$ atoms being in one plane) require angles of $178.5^{\circ}$ so that such connections are very likely to form. If it be recalled that the interior angle $\mathrm{O}-\mathrm{Si}-\mathrm{O}$ in a tetrahedron is $109^{\circ} 28^{\prime}$, it will be realized why connected tetrahedra are almost naturally adapted for the $108^{\circ}$ interior angles of plane pentagonal ring systems at the highest temperatures for the existence of connected tetrahedra. A very slight stress must exist if the $180^{\circ}$ angles tend to be maintained. Furthermore, any departure from planeness would increase rather than relieve this slight stress which prevents the extension of micro-order to crystal growth. The micro-network so formed is uniquely that of necessarily stressed small clusters of otherwise regular pentagonal dodecahedra. This is characteristic of silica-glass structure.

Another possible ring-type structure at fairly high temperatures is hexagonal. For unstressed planar rings the angles at $\mathrm{Si}-\mathrm{O}-\mathrm{Si}$ must be $169.5^{\circ}$ so that the favorable temperature for high probability of connecting tetrahedra into the form of hexagonal rings, would be appreciably lower than for forming pentagonal rings. In important contrast with pentagonal rings, the hexagonal rings, even if perchance formed with $\mathrm{Si}-\mathrm{O}-\mathrm{Si}$ angles larger than $169.5^{\circ}$, can easily become crooked and nonplanar to release the stress and thus permit the unlimited 3-dimensional growth of crystals in silicate melts.

Zarzycki [31] says that a typical infrared quartz band remains in vitreous silica held for 30 minutes at temperatures of 1750 to $1900{ }^{\circ} \mathrm{C}$ and only after treatment to above the latter temperature is the band weakened. Sosman [32] says: "Both quartz and tridymite can be melted at temperatures lower than the stable melting point of $1723^{\circ} \mathrm{C}$, but unless further heated to a higher temperature, the fused silica so produced would gradually change over into crystobalite." Also, it is known that fused silica of density 2.20 is obtained after cooling a silica melt from temperatures of $2000^{\circ} \mathrm{C}$ or higher to holding-period temperatures at or near $1800^{\circ} \mathrm{C}$ for 30 minutes.

From the above, it may be surmised that for nucleation of crystals in silica melts the coolings should be rapid through temperatures near $2000^{\circ}$ and perhaps down to about $1800^{\circ}$ or lower. On the other hand, for "nucleation" of vitron structure the maximum temperature should be near $2000^{\circ}$ or higher with slow cooling to, say, around $1900^{\circ}$ and with cooling, rapid if possible, below $1800^{\circ}$ and lower temperatures where nucleation of hexagonal structure probably occurs.

Usually nucleation means incipient crystallization in or from a well-modified essentially glassy melt. It has long been observed that heterogeneous nucleation starts and spreads rapidly from surfaces, edges, cracks, defects, flaws, fissures, or veritable crystallites with some of which melts are usually well supplied. A very small "free volume" permits "cooperative maneuvers" necessary for change of structure, step- 
wise. It is noteworthy that any contraction of $\mathrm{Si}-\mathrm{O}-\mathrm{Si}$ angles would rapidly increase free volume. It has also been insistently inferred that homogeneous nucleation can start more or less simultaneously anywhere within the body of melts.

In a discussion of nucleation (with a comprehensive bibliography), Brown and Ginell [33] conclude that good glass structure is so metastable with respect to crystal that homogeneous nucleation rarely if ever occurs. Instead, they stress the great prevalence in all real systems of heterogeneous sites at which crystallization may start.

Dietzel and Wickert [34] measured rates of crystallization as a function of modification for the $\mathrm{Na}_{2} \mathrm{O}$ $\mathrm{SiO}_{2}$ system and expressed glass tendencies as reciprocals of such rates. Their results (as shown in their fig. 1) are reproduced here as figure 3 . The

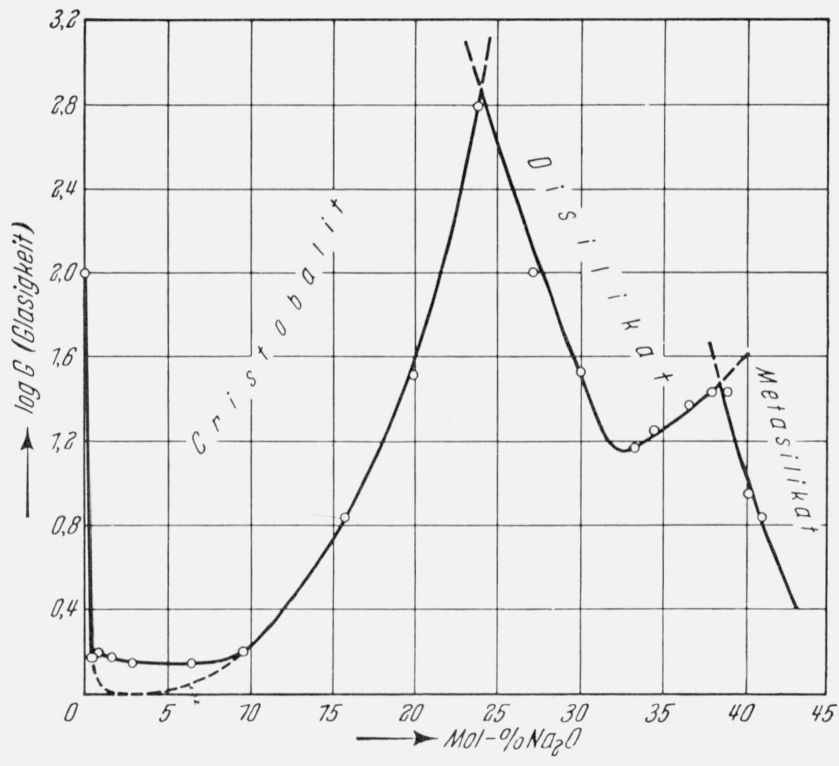

FIgURE 3. Curve of glasigkeit in $\mathrm{Na}_{2} \mathrm{O}$ binary silicates, reproduced from Bild by Dietzel and Wickert [34], may be used to illustrate the relation of vitron theory to nucleation. (See text.)

maxima of rates of glasigkeit occur at 0,24 , and 38 mole percent $\mathrm{Na}_{2} \mathrm{O}$, with a wide minimum at about 0.5 to 10 , and a sharper one at 33 mole percent. The authors mention but do not explain the unexpected abrupt fall from 100 percent silica and the wide minimum from 0.5 to 10 percent. From a vitron viewpoint, the abrupt fall, like a similar fall in viscosity, is attributable to "fissuring" and to the incipient predisposition to free volume at the peripheries of all vitrons. The maximum in glass tendency at 24 percent corresponds to oxide saturation at the glass eutectic ( 25 or 26 percent), and the less prominent one at 38 corresponds to the cation (and last) saturation before essentially complete vitron destruction. At both peaks the saturation offers maximum steric hindrance to formation of free volumes.

As pointed out by various investigators and mentioned by this writer [12(f), p. 125] in a discussion of viscosity, the conventional concept of a loosened struc- ture by the breaking of oxygen bridges as modifiers are added, is too slow and delayed to explain the first precipitate fall in viscosity or in glasigkeit. For the extreme case of only 0.5 percent $\mathrm{Na}_{2} \mathrm{O}$, only one bridge in about 400 can be broken; yet for 9 percent where one in 20 might be broken the curve of glasigkeit stands at the same very low level. The narrower valley at 33 percent marks the condition where cation concentration begins to outrun the relaxation that followed oxide saturation. The rise near 17 mole percent may be even more sudden and abrupt than appears in figure 3. Some evidence of this is found in data by Jenckel and Schwittman [35] which was discussed by this writer [12(c), pp. 362, 363]. At 16.7 mole percent $\mathrm{Na}_{2} \mathrm{O}$ one molecule of that oxide becomes available for each vitron cage and can strengthen and stiffen it by a "deep potential well" position therein.

The concept of fissuring which the writer now suggests as of great importance in nucleation of glass is essentially the same as previously postulated [12(e), p. 10]; [12(f), p. 118] to explain the maximum in partial molar volume for silica at 12 or 13 mole percent, as found by Callow [24].

Innumerable fissures can probably supply free volume permitting rearrangements necessary for the change of 5-ring tetrahedra to hexagonal linking and thus to further crystal nucleation. If one thinks of about $5 \mathrm{SiO}_{2}$ tetrahedra involved near each vulnerable fissure (or stressed region), it follows that such vulnerability can be effectively lowered by 16.7 percent modification, or about one oxide per vitron, to give steric support.

\section{Tentative Vitron Structure of Borate Glasses}

The remarkable similarity in the data of immiscibility for silicate and borate glasses stimulates a search for vitron structure in borates. Despite the similarity, there are extreme differences between silicates and borates. In silicates, after the termination of immiscibility, the liquidii fall precipitately, whereas in borates they rise. Apparently modification weakens a strong structure in silicates, but slowly substitutes a partial network instead of a molecular structure in borates. Possibly the vitron structures in $\mathrm{B}_{2} \mathrm{O}_{3}$ glass are neutral discrete molecules in large part, held together by very weak forces, and their destruction allows formation of a moderately stronger 3-dimensional network.

In 1952 Fajans and Barber [42] published a scholarly paper on boron trioxide. They concluded that a 3 dimensional network is incompatible with the low melting point and molar refraction of (pure) boron oxide, that the expansibility, surface tension, and viscosity below $1400^{\circ} \mathrm{C}$ prove that the glass below about $300^{\circ} \mathrm{C}$ consists of units held together by "weak" forces, and that with increasing temperature the structure changes gradually toward a "strong" one. They give consideration to a molecule of $\mathrm{B}_{4} \mathrm{O}_{6}$. A more recent paper by Ottar and Ruigh [43] also gives consideration to $\mathrm{B}_{4} \mathrm{O}_{6}$ cage molecules, held to each other by (weak) directed 
dative bonds between oxygen of one molecule and boron of another.

In published speculations regarding the structure of borate glasses, the equilateral triangle has often been discussed. With trivalent $B$ at the center, the three half oxygens may be located at the midpoints of the sides. Planar and lamellar structures have been proposed with the half oxygens at the apices. With oxygen at the mid sides, as in figure 4 , and dihedral

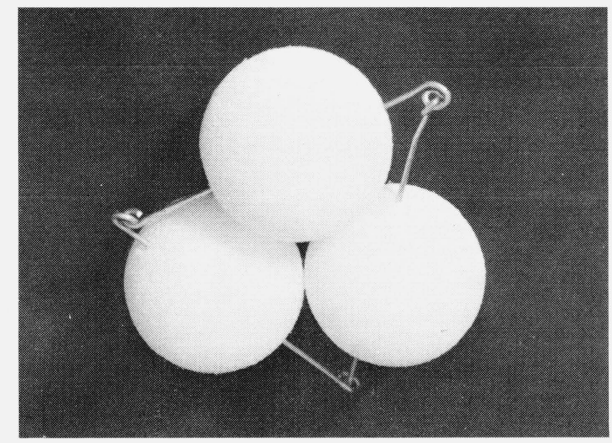

FIGURE 4. The boron-oxvgen equilateral triangle.

This is a widely accepted unit of boric-oxide glass. Each midside is the locus of (one-half) oxygen. The boron atom (not shown) lies at the triangle center.

angles of $138^{\circ} 16^{\prime}$ between the triangle surfaces, a vitron cage of triangles called an icosahedron is formed with 20 triangular faces and 30 edges. Obviously, this could be a model for a neutral-free molecule of $\left(\mathrm{B}_{4} \mathrm{O}_{6}\right)_{5}$. Figures 5, 6, and 7 show a model so constructed.

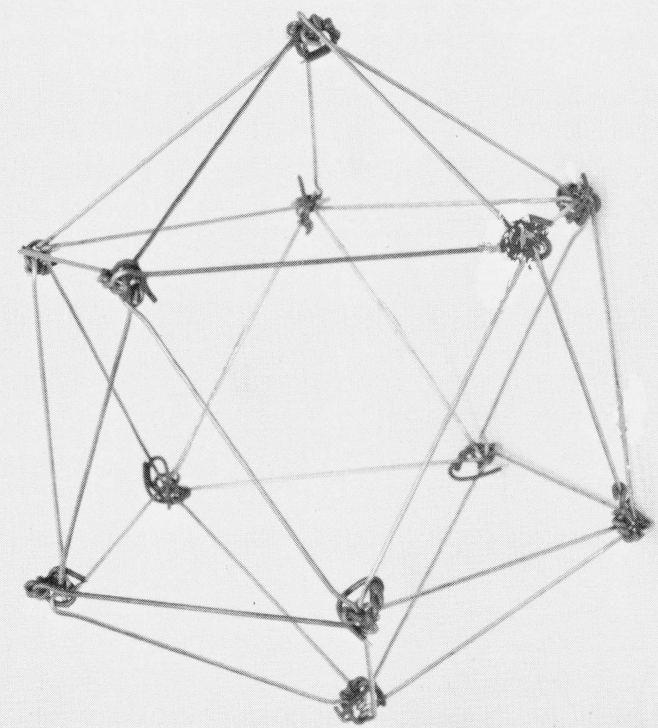

FIGURE 5. Framework of icosahedral vitron proposed for boric-oxide glass.

View along one of ten 3 -fold boron axes. There are 20 triangles united by the sharing of oxygen atoms.

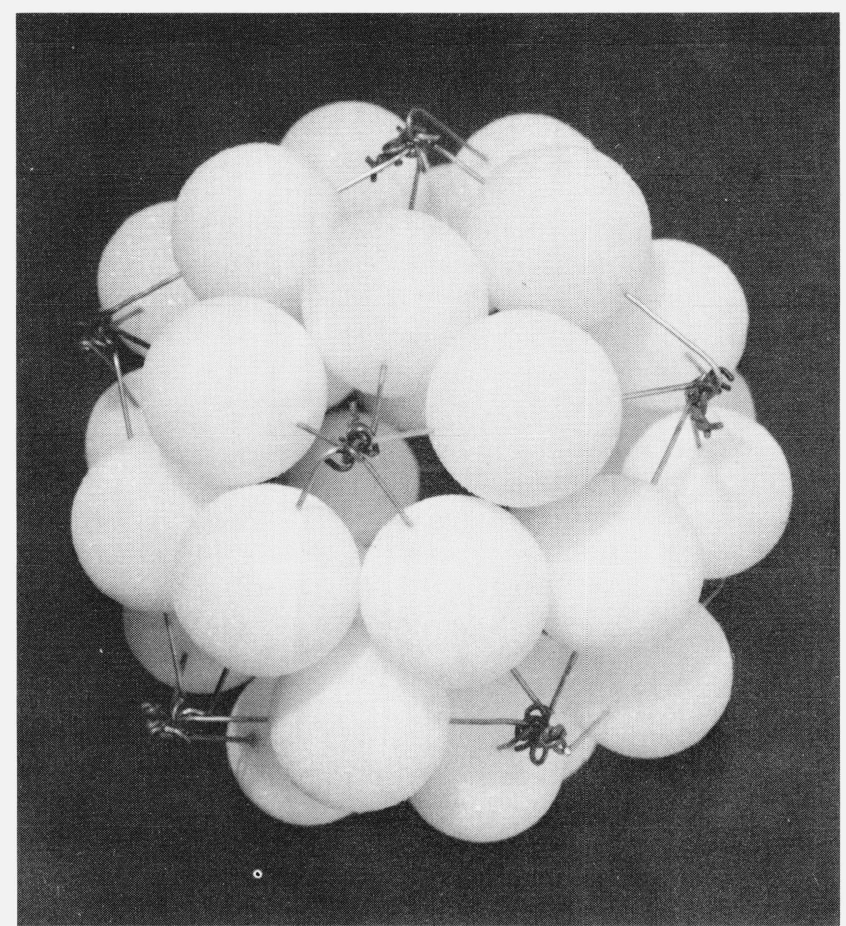

Figure 6. Proposed empty vitron for boric-oxide glass.

Thirty oxygens are mounted on the framework of figure 5. With twenty borons (not shown) this forms a neutral molecule of $\left(\mathrm{B}_{4} \mathrm{O}_{6}\right)_{5}$.

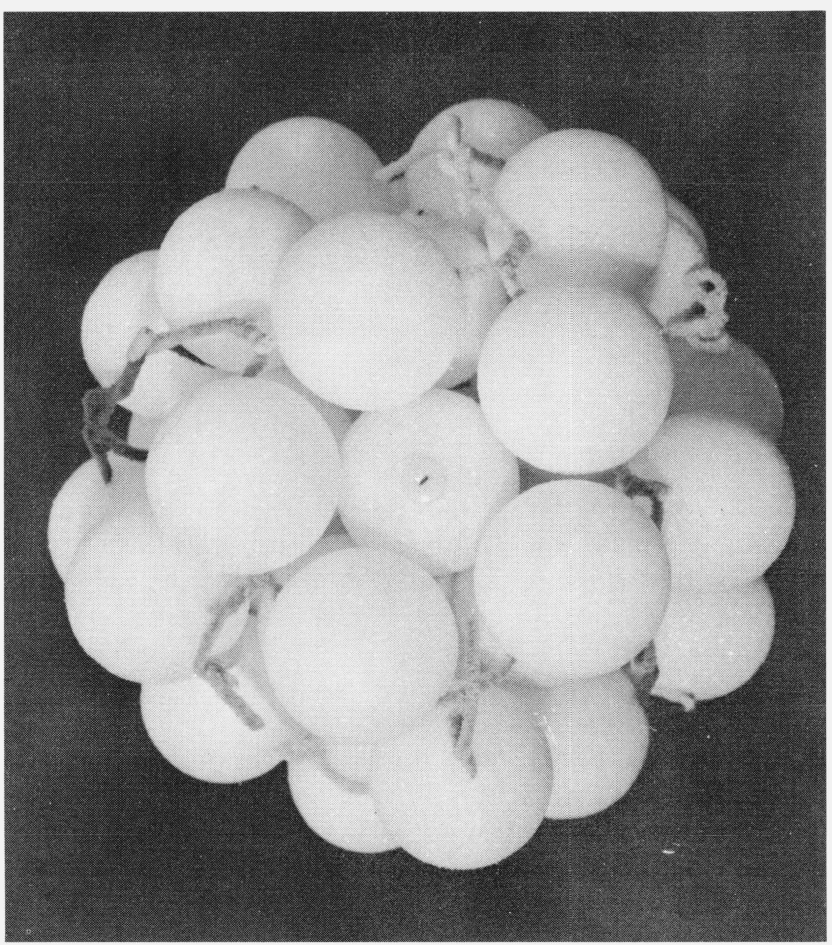

Figure 7. Proposed vitron fully modified by an oxide having very small cations (not shown).

Thirteen oxide molecules ai most may be placed in the cavity of figure 6 . (The wire framework has been replaced by tie lines which are regrettably in evidence.)

Radial-distribution data from diffraction patterns on borates are not numerous and not very consistent, but 
there seems to be a consensus for a B-O distance of 1.39 or $1.40 \AA$ (which is less than $\Sigma$ radii) in boric-oxide glass (with a spread toward higher values, up to 1.48, depending on degree of modification).

If the scale factor for the icosahedron is taken from 1.40 for the $\mathrm{B}-\mathrm{O}$ distance, the edge length is $4.85 \AA$ and the volume is $249 \mathrm{cu} \AA$. This compares with $251 \mathrm{cu} \AA$ as published in 1957 for the volume of the dodecahedral vitron of silica. This would show why eqs (3) and (4) of section 3 in this paper with the same values for parameter $A$ and for $\alpha$ can be used for borates as well as silicates.

A second regular solid made up of 8 equilateral triangles is the octahedron, figure 8 . This might serve as the secondary structure in the matrix of boric-oxide glass. With the same arrangement of $B$ at 8 face centers and oxygen at the 12 midedges, it would be a model for $\left(\mathrm{B}_{4} \mathrm{O}_{6}\right)_{2}$ and again a free neutral molecule, figure 9.

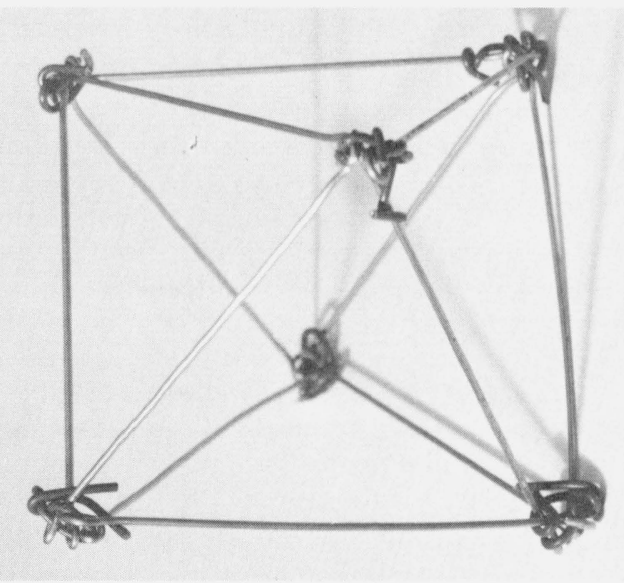

FigURE 8. Framework of octahedral structure proposed for part of matrix of boric-oxide glass.

There are 8 triangles united by the sharing of oxygen atoms at the midedges.

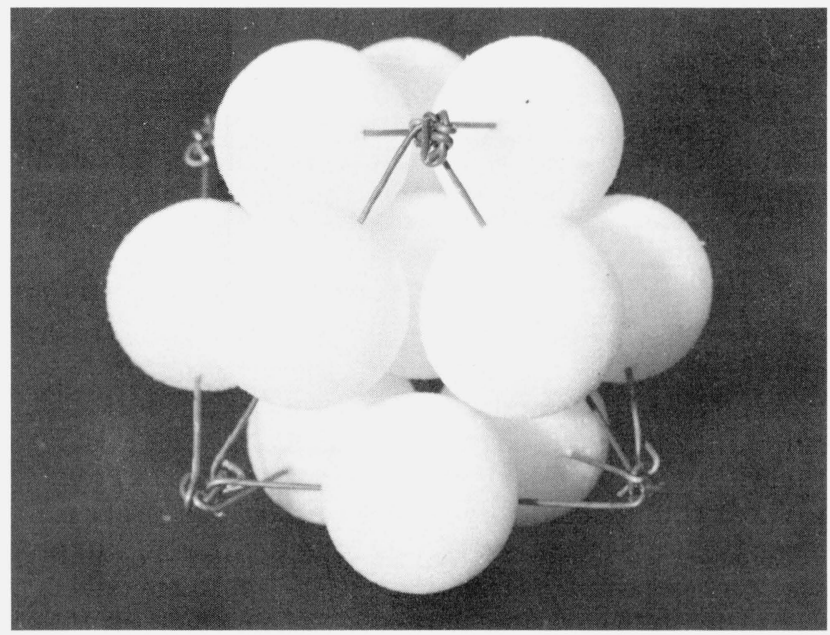

Figure 9. Proposed octahedral siructure for part of the matrix of boric-oxide glass.

Twelve oxygens are mounted on the framework of figure 8. With eight borons (not shown) this forms a neutral molecule of $\left(\mathrm{B}_{4} \mathrm{O}_{6}\right)_{2}$. An oxygen atom is inclosed at center to show that the hole is somewhat larger than $2.8 \AA$ in diameter. According to eq (4) of Section 3 above, the hole should have a diameter of approximately $\alpha=3.56 \AA$.
Remembering that the dihedral angle is only $109.5^{\circ}$, the scale factor may become larger than for the triangles of the icosahedron in order, after modification, to make room inside the octahedra for the oxygens and leave at the center of the cluster an aperture, or hole, approximately $\alpha \AA$ in effective diameter and capable of inclosing an oxygen and a small cation like beryllium.

When soda modifiers are added not in excess of those retainable as guests in the icosahedra, it has been said that the boron may become 4-coordinated and some triangles add oxygen and become boron-oxygen tetrahedra joined by bridges into a coordinative network. However, there seems no direct evidence that tetrahedra are actually formed in borate glasses, or that a really strong coordinative network exists at any temperature or degree of modification.

Warren and associates [45] measured the (B-O) distance in boric-oxide glass as $1.39 \mathrm{~A}$ which he compared with 1.36 in some crystalline borates. A boronoxygen equilateral triangle, even with $(B-O)=1.40$ $\AA$, certainly means interpenetration of electron clouds of adjacent atoms. Warren also found a peak at $2.42 \AA$ for $(\mathrm{O}-\mathrm{O})$ distance which likewise indicates interpenetration. Then for $(\mathrm{B}-2 \mathrm{dO})$ he found 3.75 . In the icosahedra, or large molecules, the last distance is 4.16 for the scale adopted and in the octahedra $3.13 \AA$. These results are tabulated below.

TABLE IV

\begin{tabular}{l|c|c|c|c}
\hline \hline Distance & Octahedra & Icosahedra & Average & Warren \\
\hline (B-O) & 1.40 & 1.40 & 1.40 & 1.39 \\
(B-B) & 2.27 & 2.61 & 2.44 & 2.42 \\
(O-O) & 2.42 & 2.42 & 2.42 \\
$(\mathrm{~B}-2 \mathrm{dO})$ & 3.13 & 4.16 & 3.65 & \\
$(\mathrm{~B}-2 \mathrm{~dB})$ & 3.23 & 4.21 & 3.72 & 3.75 \\
$(\mathrm{O}-2 \mathrm{dO})$ & 3.42 & 3.92 & 3.67 & \\
\hline
\end{tabular}

All initial distances of near-neighbor atoms in $\mathrm{B}_{2} \mathrm{O}_{3}$ glass seem to indicate a state of compression. Shartsis, Capps, and Spinner [47] remark, from other considerations, that "the glass should act as if it were under pressure." Biscoe and Warren [46] reported that the (B-O) distance first decreased and then increased progressively from 1.37 to $1.48 \AA$ as modifier content of $\mathrm{Na}_{2} \mathrm{O}$ in $\mathrm{B}_{2} \mathrm{O}_{3}$ was increased from 10 to 31 mole percent, and that the coordination of boron ${ }^{8}$ also increased. This may mean merely that some $(\mathrm{B}-\mathrm{O})$ bonds decreased in strength and that the concentration of oxygen atoms in the cavities must increase the apparent coordination of boron. These and other reported effects and the so-called boron-oxide anomalies, such as maxima and minima on property composition curves, are probably explainable in terms of some of the following:

\footnotetext{
${ }^{8}$ If the 4-coordination of boron is supposedly affected by an oxygen bridge from $B$ of one molecule to $\mathrm{B}$ of another molecule and the B atoms pulled out of their original triangular plane so that the new $(\mathrm{B}-\mathrm{O})$ distances are increased from 1.40 to $1.48 \AA$ (Briscoe and $\mathrm{W}$ arren's report), then each boron need be displaced only $0.44 \AA$ from the original plane instead of $0.96 \AA$ for a symmetrical tetrahedron.
} 
(1) Increasing concentration of modifiers isolated in cavities as their respective capacities are approached (see $100 r_{h}$ as specified by eq (4) and listed in table II);

(2) Dearth of ionization and expansion before cavity capacities are reached;

(3) Stress of B-O bonds beginning with 4-coordination of boron and rapidly increasing at cavity capacity;

(4) Continuous breakup of vitrons and increase in ionization and in volume expansion that begins near cavity capacity and extends to much higher modifications.

To test the proposed models for density is difficult, particularly because of the unknown packing factor. According to eq (4), the value for $q$, that is the percentage of $\left(\mathrm{B}_{2} \mathrm{O}_{3}\right)$ in icosahedral form, is 38 . If it be assumed that the atoms in an icosahedral molecule are all contained in the circum circle of $D=9.2 \mathrm{~A}$, then the density of the vitron portion is 2.83. Similarly, an estimate of the octahedral portion is 2.73 , but all suggested about its extent in boric-oxide glass is that it forms a part of the matrix of 62 mole percentperhaps a large part. If the remainder is loosely connected random fragments of $\mathrm{B}_{2} \mathrm{O}_{3}$, the whole matrix might have a density of 2.73 , which gives about 2.76 for the combination. This, of course, would require almost perfect packing of approximately spherical molecules and particles of 2 or 3 sizes. For a reasonable estimate of one-third of total volume as very small interstitial voids, the computed density reduces to 1.83 in agreement with measured values [52] at room temperature.

The cavities of vitrons are soon effectively filled when modification is caused by alkalies. Moreover, some ionization starts early for alkalies and for barium oxide because immiscibility is not complete but only a metastable tendency. Consequently, some modifier $\mathrm{O}^{2-}$ is soon trapped at the octahedral centers so that in effect some atoms of $\mathrm{B}^{3+}$ become 4-coordinated (perhaps with one bond longer than the others) and thus share their charge with 4 oxygen atoms. Some oxygens of the octahedral molecule are therefore not fully satisfied and the modifier alkali or barium atoms may become loosely attached at apices of the octahedra. Each such molecule will have a residual plus charge that can be useful in establishing weak connections with other elements of the matrix during subsequent degradation of the orderly arrangements in icosahedra.

The distance between extreme apices of octahedra in borates is $6.5 \AA$, and that between adjacent apices is $4.8 \AA$. Bienenstock, Posner, and Block [48] reported (Ba-Ba) distances of $6.76 \AA$ in a 20 mole-percent barium borate glass in 1960; and, similarly, Piermarini and Block [49] reported 6.8 and $4.7 \AA$ in a 24 molepercent barium borosilicate glass in 1962. Also, Krogh Moe [50] reported a $(\mathrm{Ba}-\mathrm{Ba})$ distance of $6.9 \AA$ in a barium borate glass in 1962 .

$\mathrm{BaO}$ resembles the alkalies in that the miscibility is metastable and there is only a tendency thereto, and some ionization probably starts before vitron capacity is reached. For example, when $\mathrm{BaO}$ is the modifier, no 2-liquid layer appears. Inflection of the S-shaped liquidus occurs near 16 mole-percent modification for borates and near 15 percent for silicates. Icosahedral disintegration is well underway at 24 percent. Krogh Moe [50] refers to similar experiments with cesium oxide which should be even more conclusive on this point.

The experimental evidence just cited suggests that the octahedral molecules are more stable than the icosahedra and exist intact after the latter are partially broken up by modification.

Unquestionably the destruction of order in glasses can be caused by high temperature as well as by the process of modification. At present, experiments do not permit so precise an account of temperature effects as have been given for the modification process which has been empirically practiced for many decades. Possibly, in terms of the models herein presented, a temperature hypothesis may be formulated.

At room temperatures the molecular vitrons of boricoxide glass may be held to each other by numerous intermolecular bonds, perhaps the dative bonds between oxygen of one molecule and boron of an adjacent molecule, as suggested by Fajans and Barber [42] and discussed in more detail by Ottar and Ruigh [43]. When temperatures are held below about $300{ }^{\circ} \mathrm{C}$, borate glass is in a rigid state and there is little expansion in volume. For this region Macedo and Napolitano [51] have reported an apparent activation energy of some $90 \mathrm{kcal}$ per mole for viscous flow. This may be, as suggested by Ottar and Ruigh [43], the combined simultaneous breaking of a number of intermolecular dative bonds.

Then rather suddenly, as the glass softens at higher temperatures, rapid expansion takes place because some of the icosahedral bonds, which have been stressed beyond their breaking length, begin to part. Because of the varying stresses in different parts of these vitrons, there may be a distribution of activation energies with an average value steadily decreasing as the disordering process proceeds at ever-increasing temperatures while the volume expansion gradually slows at temperatures above softening. Then the end of the non-Arrhenius region is reached and activation energies again tend toward constancy at 700 or $800{ }^{\circ} \mathrm{C}$. The (computed [51]) terminal value of say $18 \mathrm{kcal}$ may relate to flow within the matrix consisting of octahedral molecules $\left(\mathrm{B}_{4} \mathrm{O}_{6}\right)_{2}$, immersed in a proportionately much larger matrix including fragments of the disrupted icosahedra. This is in accord with modern theories of structure of glass in that there is a growing tendency to consider that some glass structures are already well formed in the melt above liquidus temperatures.

At present, experiments do not permit desirably direct examination of this high-temperature hypothesis. The successful quantitative use of eq (4) of this paper does reveal the nature of a close relation between such different glasses as silicates and borates. It is also quantitatively consistent with the fundamental nature 
and function of glass modifiers and indicates methods for investigating structure in other glass-former glasses.

\section{Concluding Remarks}

This paper concludes the detailed reports on vitron theory as developed chiefly between 1955 and 1958 . Its publication has been delayed partly in futile attempts to arrange for experiments leading to pertinent quantitative high-temperature studies of details of immiscibility and related manifestations of departures from ideality in silicate and borate melts, including the size, shape, and location of domes of immiscibility above liquidus temperatures for the several modifying oxides, and under conditions for possible variations in the existing vitron-to-matrix equilibrium.

From the vitron viewpoint, the report by Dietzel and Wickert on glasigkeit, and especially their curve therefor in figure 3 (above), is very significant. It stimulates a few very comprehensive remarks about glass.

The presence of vitrons, which initially tend to make it difficult for crystals to form, is later not advantageous in their undamaged state for making the best glasses. The example is pure silica glass which is easily made without crystallization, but is somewhat lacking in ultimate uniformity. The best silicate glasses are made by modifications of vitrons carried to a limit that alters the vitrons and thus slowly, without completely destroying them, reduces the abruptness of transition from vitron to matrix. Immediately and suddenly after oxide saturation near or at the eutectic, the ionization and bridge-breaking seriously damage the vitrons and this begins to favor the rearrangements of crystallization. Probably some $\mathrm{Si}-\mathrm{O}-\mathrm{Si}$ angles contract. This and/or the pressure of increased cation particles briefly outrun the loosening tendencies, reduces free volume, and thus continues to favor glass formation for a short range in added modification. Thereafter, with further modification, good glassmaking is very soon ended. Rigidity and/or particle pressure seem to oppose formation of free volume, low temperatures reduce nucleation rates, and remaining goodly proportions of pentagonal ring structure of the tetrahedra greatly retard the formation of hexagonal rings and hence of crystals.

With this concept of glass, it can be said that glass formers, of the $\mathrm{SiO}_{2}$ and $\mathrm{B}_{2} \mathrm{O}_{3}$ types, are those that can and do form distorted cages (such as pentagonal dodecahedra and icosahedra) that are almost but not exactly of crystalline form. Glass modifiers are oxides that can by mere quantity progressively (and advantageously) modify the properties of such noncrystal structures and can even partially (and advantageously) disrupt their quasi-crystalline degree of order.

Can it be that crystallization would predominate at all degrees of modification if elemental arrangements of quasi-crystalline structures were not present? The series of seven papers of which this one is the last is founded upon that hypothesis. Without some phenomenon to block the iterative processes of crystallization, inorganic glasses would not exist. Their characteristically small molecules would fit instead into one of a large number of potential repetitive crystalline structures.

\section{References}

[1] Greig, J. W., Am. J. Sci. 73, 1 (1927).

[2] Kracek, F. C., J. Am. Chem. Soc. 52, 1436 (1930).

[3] Warren, B. E., and Pincus, A. G., J. Am. Ceram. Soc. 23, 301 (1940).

[4] Dietzel, A., Z. Electrochem. 48, 9 (1942).

[5] Levin, Ernest M., and Block, Stanley, J. Am. Ceram. Soc. 40, 95 (1957). Levin, E. M., Phys. and Chem. of Glasses 7, 92 (1966).

[6] Glaser, F. P., Warsaw, J., and Roy, R., Phys. and Chem. of Glasses 1, 39 (1960).

[7] Preston, Eric, J. Soc. Glass Techn. Trans. 26, 82 (1942).

[8] Esin, O. A., J. Phys. Chem. 22, 617 (1948).

[9] Forland, Tormond, Techn. Report No. 63, Office of Naval Research, NR 032-264; Penna. State Univ., College of Mineral Industries. pp. 11, 16, 23 (1955).

[10] Dietzel, A., Naturwis. 31, 110, 112 (1943).

[11] Dietzel, A., and Sheybany, H. A., Verres et Réfractaires 2, 6380 (1948).

[12] Tilton, L. W.

(a) J. Soc. Glass Techn. 40, T338 (1956);

(b) Opt. Soc. Am. Annual Meeting, Oct. 1956. J. Opt. Soc. Am. Abst. 47, 115 (1957); J. Research NBS 59, 139 (1957) RP2782;

(c) J. Research NBS 60,351 (1958) RP2854;

(d) J. Research NBS 61, 463 (1958) RP2915;

(e) J. Am. Ceram. Soc. 43, 9 (1960);

(f) J. Res. Nat. Bur. Stand. (U.S.), 65A (Phys. and Chem.), No. 2, 117 (Mar--Apr. 1961);

(g) Encyclopedia of X-Rays and Gamma Rays, Ed. George L. Clark, 430-436, (Reinhold Publ. Corp., N.Y., 1965).

[13] Warren, B. E., Z. Krist. 86, 349 (1933); J. Am. Ceram. Soc. 17,249 (1934).

[14] Bernal, J. D., Nature 185, 68 (1960).

[15] Ginell, R., J. Chem. Physics 34, 999 (1961).

[16] Mackenzie, J. D., Chemical Reviews 56, 456 (1956).

[17] Douglas, R. W., Non-Crystalline Solids, 382. (John Wiley \& Sons, Inc., N.Y., 1960).

[18] Kracek, F. C., J. Am. Chem. Soc. 52, 1438-42 (1930).

[19] Moore, Walter J., Physical Chemistry, 317 (Prentice-Hall Inc., 1958).

[20] Bockris, J. O'M., Tomlinson, J. W., and White, J. L., Trans. Faraday Soc. 52, 299 (1956).

[21] White, J. L., PhD thesis, Univ. of Cal. 1955.

[22] Tomlinson, J. W., Heynes, M. S. R., and Bockris, J. O'M., Trans. Faraday Soc. 54, 2218 (1958).

[23] Simon, I., and McMahon, H. O., J. Am. Ceram. Soc. 36, 160-164 (1953).

[24] Callow, R. J., J. Soc. Glass Techn. 36, T137-4l (1952).

[25] Hill, O. F., and Audrieth, L. F., J. Phys. \& Colloid Chem. 54, 690-96 (1950).

[26] White, J., Howat, D. D., and Hay, R., J. Roy. Tech. Coll. Glasgow 3, 239 (1933-36).

[27] Aramaki, Shigeo, and Roy, Rustum, J. Am. Ceram. Soc. 42, 644 (1959).

[28] Levin, Ernest M., and McDaniel, Clyde L., J. Am. Ceram. Soc. 45, 355 (1962).

[29] Toropov, N. A., The Structure of Glass (Translated from Russian), 285. Acad. Sci. USSR Press, Moscow-Leningrad 1953.

[30] Bergman, A. G., The Structure of Glass (Translated from Russian), 246. Acad. Sci. USSR Press, Moscow-Leningrad 1953.

[31] Zarzycki, J., Verres et Réfractaires 11, 3 (1957).

[32] Sosman, R. B., Encyl. Britannica, 1955.

[33] Brown, S. D., and Ginell, Robt., Preprint, Am. Ceram. Soc. Toronto Meeting, 1961. 
[34] Dietzel, Adolf, and Weikert, Helmut, Glastechn. Berichte 29, 3 (1956).

[35] Jenckel, E., and Schwittman, A., Glastechn. Berichte 16, 168 (1938).

[36] Mandelcorn, Lyon, Non-stoichmetric Compounds, 309, 314 (Academic Press, New York, 1964).

[37] Levin, Ernest M., Robbins, Carl R., and Waring, Jon L., J. Am. Ceram. Soc. 44, 87 (1961).

[38] McClure, J. H., J. Phys. Chem. Solids 24, 871 (1963).

[39] Nassau, K., J. Phys. Chem. Solids 24, 1511 (1963).

[40] Moeller, Therold, The Chemistry of the Lanthanides, 44 (Reinhold Publ. Corp., New York, 1963).

[41] Cohen, A. J., VII International Congress on Glass, Brussels, 1965.

[42] Fajans, K., and Barber, S. W., J. Am. Chem. Soc. 74, 2761 (1952).

[43] Ottar, B., and Ruigh, W. L., Phys. and Chem. of Glasses 3, 95 (1962).

[44] Shafer, M. V., and Suits, J. C., J. Am. Ceram. Soc. 49, 262 (1966).
[45] Warren, B. E., Krutter, H., and Morningstar, O., J. Am. Ceram. Soc. 19, 202 (1936).

[46] Biscoe, J., and Warren, B. E., J. Am. Ceram. Soc. 21, 287 (1938).

[47] Shartsis, L., Capps, W., and Spinner, S., J. Am. Ceram. Soc. 36, 40 (1953).

[48] Bienenstock, A., Posner, A. S., and Block, Stanley, J. Research N.B.S. 64A, $229(1960)$.

[49] Piermarini, G. J., and Block, S., J. Res. Nat. Bur. Stand. (U.S.), 67A (Phys. and Chem.), No. 1, 37 (1963).

[50] Moe, J. Krough, Physics and Chemistry of Glasses 3, 208 (1962).

[51] Macedo, P. B., and Napolitano, A., J. Chem. Physics 49, 1887 (1968).

[52] Macedo, P. B., Caps, W., and Litovitz, T. A., J. Chem. Physics 44, 3357 (1956).

[53] Olshansky, Ya., Proc. Acad. Sci. USSR 75, 93 (1951).

[54] Aherns, L. H., Geochim. Cosmochim. Acta 2, 155 (1952).

(Paper 77A2-769) 